\title{
Comentários à decisão do Tribunal de Justiça do Estado do Rio Grande do Sul Sobre o Caso da Esteira Térmica
}

Ediná Alves Costa ${ }^{(*)}$

Nesta decisão, do Tribunal de Justiça do Estado do Rio Grande do Sul, reconhece-se o inalienável direito do cidadão de ser informado sobre

$\left(^{*}\right)$ Professora do Instituto de Saúde Coletiva da Universidade Federal da Bahia. E-mail: <edina@ufba.br>. Recebido em 11.12.08. Aprovado em 10.1.09. 
os riscos à saúde que porta um determinado objeto de consumo, neste caso, um aparelho denominado "esteira térmica anatômica massageadora". E assim, a um tempo afirma-se a responsabilidade civil da empresa envolvida na transação comercial que resultou na exposição da compradora a risco de danos à sua saúde, por ser portadora de cardiopatia, condição que contra-indicava o uso do equipamento. Encaminhamento claro, preciso, justo: rescindido o contrato de compra e venda, igualmente se desfaz o contrato de financiamento bancário, posto que desfeita a transação comercial que o motivou. O reconhecimento de danos morais, a que foi submetida a compradora, conduziu à condenação das empresas responsáveis pelo aparelho em questão ao pagamento de um valor pecuniário, que embora modesto, remete à responsabilidade civil dos agentes econômicos envolvidos, sublinhada por se tratar de expor a compradora de seu produto a sério risco de danos à sua saúde.

Este caso nos conduz a refletir sobre um conjunto de processos decorrentes das relações sociais produção-consumo na sociedade contemporânea, a chamada sociedade de risco e também sociedade de consumo, e, particularmente, sobre aspectos da formação social brasileira que experimenta um processo tardio de construção de uma consciência cidadã e sanitária. Por conta disso, verifica-se, frequentemente, a ocorrência de condutas ilícitas de agentes econômicos pouco respeitosos para com os direitos dos cidadãos e consumidores, possivelmente em maior grau que em outros países, ditos desenvolvidos. Também permanece certa complacência do Estado que ainda não provê a sociedade dos meios e estratégias necessários à proteção da saúde da população e elevação de sua consciência sanitária. ${ }^{(1)}$

Atualmente, sob poderosas estratégias comerciais, uma pletora de produtos, tecnologias e serviços é ofertada no mercado de consumo, em nome da saúde, sob alegados benefícios. Neste contexto, a saúde é tanto um valor juridicamente protegido, como também uma mercadoria e, assim, produtos e serviços de saúde ou indiretamente relacionados com a saúde, como objeto de comércio, passam a adquirir novos significados que lhes são atribuídos, muitas vezes desfavoráveis à saúde. O medicamento, por exemplo, como mercadoria simbólica, é destituído dos riscos que lhe são inerentes e passa a significar cura. Assim, as farmácias, que deveriam ser estabelecimentos de saúde, abarrotadas de mercadorias, vendem "saúde, beleza, higiene". Possuir um determinado Plano de Saúde ou ter acesso aos serviços de saúde significa ter saúde. A saúde enfim, como diz Lefèvre ${ }^{(2)}$, torna-se um objeto de desejo disponível no mercado.

(1) COSTA, E. A. Vigilância sanitária: proteção e defesa da saúde. São Paulo: Sobravime, 2004.

(2) LEFÈVRE, F. Mitologia sanitária. São Paulo: Edusp, 1999. 
E as estratégias do mercado, voltadas a estimular o consumo, em geral tendem a descaracterizar os riscos potenciais desses bens que são quase sempre apresentados tão somente nos seus aspectos benéficos. Os riscos intrínsecos de muitos dos bens relacionados com a saúde podem, ainda, ser acrescidos de outros tantos, decorrentes de condutas humanas inadequadas ou mesmo criminosas, incidentes sobre qualquer momento do ciclo produtivo dos bens, da produção à comercialização e consumo. Omitir informações a respeito desses riscos é uma dessas condutas mais frequentemente observadas.

Estes processos requerem, cada vez mais, o incremento da função regulatória do Estado, o estabelecimento de normas jurídicas que proíbem e/ou condicionam comportamentos humanos relacionados com os bens de interesse da saúde, assim como também requerem a organização e implementação de serviços efetivos para as ações de fiscalização, controle de riscos e proteção da saúde. Tais serviços, existentes nas sociedades minimamente desenvolvidas, adquiriram, no Brasil, a denominação de vigilância sanitária e vêm sendo objeto de demanda social, à medida que cresce a consciência de cidadania. Esta vertente da intervenção estatal na saúde adquire cada vez mais importância no contexto atual da economia globalizada, mas tem sua dinâmica organizacional condicionada social e historicamente.

Diversificadas situações envolvendo relações de consumo que expõem o cidadão a riscos à sua saúde, e não raramente a danos, ocorrem em todo o mundo, mas especialmente nos países que experimentaram negação da cidadania e atrasos nos processos de sua construção, como se pode considerar o Brasil. Aproximava-se o final do século vinte, quando a saúde foi proclamada, no Brasil, um direito social e um dever do Estado, reconhecendo-se, igualmente, a defesa do consumidor entre esses deveres. Em consequência, novos marcos foram estabelecidos no direito, criando outras bases para a proteção social: assim, o direito sanitário e o direito do consumidor se entrelaçam para proteger a vida do cidadão como um valor reconhecido e legitimado no ordenamento jurídico do país, que se alinha com os povos que reconhecem a saúde como essencial à dignidade humana.

Pode-se facilmente constatar que o Brasil avançou na elaboração de suas leis de proteção social no âmbito da saúde, mas ainda existe um descompasso, entre estas e a organização dos serviços correspondentes ou entre os direitos e deveres nas leis estabelecidas e a apropriação e fruição dos direitos, por parte de cidadãos e consumidores. Também se constata a falta de assunção de suas responsabilidades, por parte de agentes econômicos, para que haja respeito à dignidade, saúde e segurança dos consumidores, bem como aos seus interesses econômicos. É fácil verificar na página eletrônica da ANVISA, o cotidiano das ilicitudes de numerosos agentes econômicos que insistem em desrespeitar as leis que visam a proteger a saúde dos cidadãos. Sequer se intimidam face à possibilidade de responderem por crimes hediondos, pois, com frequência, falsificam medicamentos. 
O texto constitucional reconhece que a saúde depende da capacidade de o Estado formular e implementar políticas públicas sociais e econômicas que visem à redução do risco de doenças e outros agravos, e também, pela garantia a todos, em igualdade de condições, do acesso a ações e serviços não apenas para a recuperação da saúde, mas também para a proteção e promoção. Afirmou-se a prioridade das ações preventivas, entre as quais se situam, com destaque, as ações de vigilância sanitária, exatamente porque se reportam principalmente ao controle de riscos à saúde individual e coletiva. Cabe à vigilância sanitária uma função fundamental na defesa dos direitos dos consumidores, na proteção de sua saúde e segurança e assim seus órgãos da esfera da União, estados, municípios e Distrito Federal integram conceitualmente o Sistema Nacional de Defesa do Consumidor (SNDC) e estão legitimados para agir judicialmente na defesa da saúde do consumidor.

Entre as tarefas atribuídas, na Constituição, ao Estado, o Sistema Único de Saúde tem a obrigação de regular, fiscalizar e controlar as ações e serviços de saúde, de natureza pública ou privada, bem como controlar e fiscalizar procedimentos, produtos e substâncias de interesse da saúde. Também foi estabelecida a obrigatoriedade de o Estado regular a propaganda de produtos, práticas e serviços que possam ser nocivos à saúde e ao meio ambiente. No entanto, o Sistema Nacional de Vigilância Sanitária, atribuído dessas tarefas, ainda não se efetivou no país. A estrutura da maioria desses serviços é muito frágil, o que pode ser constatado com os resultados do Censo dos Trabalhadores de Vigilância Sanitária, realizado em 2004. Verificou-se que $67,2 \%$ desses trabalhadores têm nível médio ou elementar. No conjunto dos trabalhadores, $19 \%$ deles nunca haviam participado de algum curso que os preparasse para exercer uma função tão complexa e $23 \%$ haviam participado de algum curso há mais de dois anos.

Por seu lado, o Sistema Nacional de Defesa do Consumidor ainda não é realidade na maioria dos municípios brasileiros, onde estão consumidores e cidadãos, dificultando o acesso aos instrumentos e estratégias que permitiriam sua defesa e proteção na ocorrência de violação de seus direitos. A implementação desses serviços é uma condição essencial para dar vida ao Código de Defesa do Consumidor, instituído no Brasil, na última década do século $\mathrm{XX}$.

As complexas relações sociais produção-consumo nas sociedades contemporâneas levam, inexoravelmente, ao reconhecimento da vulnerabilidade do consumidor no mercado de consumo, à afirmação dos seus direitos e exigência de organização de serviços e instrumentos que permitam a sua defesa e proteção. Tal vulnerabilidade é potencializada pela assimetria de informações pari passu com a complexidade do objeto de consumo. Os medicamentos e outras tecnologias médicas são emblemáticos exemplos dessa problemática: cada vez mais potentes, são capazes de produzir significativos benefícios, mas também danos à saúde, sobretudo se usados 
de modo não racional. O uso irracional dessas tecnologias é facilitado pelas estratégias de mercado; desse modo, as informações divulgadas pelo segmento produtivo e agências de publicidade acerca de produtos e serviços de interesse da saúde, são também objeto de controle sanitário, exemplo de intervenção do Estado recém-iniciada no país.

A legislação de vigilância sanitária estabelece as regras para os que querem atuar na produção e comércio de um amplo conjunto de produtos relacionados com a saúde. O objeto da transação comercial em questão, "esteira térmica anatômica massageadora" é enquadrado entre os produtos sob vigilância sanitária, definido na Lei n. 5.991, de 17 de dezembro de 1973, na classe de correlatos. Esta lei foi regulamentada pelo Decreto $n$. 74.170, de 10 de junho de 1974 e dispõe sobre o controle sanitário do comércio de drogas, medicamentos, insumos farmacêuticos e correlatos, e dá outras providências e apresenta a seguinte definição:

Correlato - a substância, produto, aparelho ou acessório não enquadrado nos conceitos anteriores, cujo uso ou aplicação esteja ligado à defesa e proteção da saúde individual ou coletiva, à higiene pessoal ou de ambientes, ou a fins diagnósticos e analíticos, os cosméticos e perfumes, e ainda, os produtos dietéticos, óticos, de acústica médica, odontológicos e veterinários.

A Lei n. 6.360, de 23 de setembro de 1976, dedicada especialmente às regras para a produção, dispõe sobre a vigilância sanitária a que ficam sujeitos os produtos acima citados e outros. Ao dispor sobre o registro de correlatos o art. 25 estabelece que:

Os aparelhos, instrumentos e acessórios usados em medicina, odontologia e atividades afins, bem como nas de educação física, embelezamento ou correção estética, somente poderão ser fabricados, ou importados, para entrega ao consumo e exposição à venda, depois que o Ministério da Saúde se pronunciar sobre a obrigatoriedade ou não do registro.

Aqueles produtos que forem dispensados de registro(3) ficam, porém, sujeitos, para os demais efeitos da lei e de seu regulamento, a regime de vigilância sanitária. Tal regime abrange a rotulagem, as bulas, os impressos, as etiquetas e os prospectos referentes aos produtos, bem como a propaganda e a publicidade dos produtos e das marcas, sob qualquer forma de divulgação e meio de comunicação.

As regras fixadas para o registro dos produtos sob vigilância sanitária expressam uma preocupação central com as informações sobre as empre-

(3) São dispensados do registro os aparelhos, instrumentos ou acessórios de que trata este artigo, que figurem em relações elaboradas pelo órgão de vigilância sanitária competente do Ministério da Saúde, ficando, porém, para os demais efeitos da Lei n. 6.360, de 23 de setembro de 1976, e deste Regulamento, sujeitos ao regime de vigilância sanitária. 
sas e seus produtos, em especial no concernente à explicitação de "contraindicações e efeitos colaterais", quando for o caso, como consta no Decreto n. 79.094, de 5 de janeiro de 1977, que regulamenta a Lei n. 6.360/76. Essas preocupações se expressam no art. 36 deste decreto que especifica as regras da obrigatoriedade de registro quando os aparelhos, instrumentos ou acessórios dependerem de prescrição médica, de cuidados especiais de aplicação ou da observação de precauções, sem as quais possam produzir danos à saúde.(4)

Observa-se, nestas regras, a preocupação com o dever de informar que têm todos aqueles que lidam com bens relacionados com a saúde. A informação é um direito do cidadão, de importância exponencial em relações assimétricas como são as relações de consumo, sobretudo no campo da saúde. É também um elemento básico das medidas preventivas que são requeridas em todas as atividades relacionadas a bens e serviços que portam riscos à saúde. Esses riscos são a razão de ser dos cuidados que a vigilância sanitária exige de todos os que pretendem atuar com esses bens.

Além da questão que objetivou a demanda jurídica por parte da consumidora, seria relevante investigar, também, se outros aspectos relativos ao controle sanitário do próprio aparelho não estão envolvidos. Isto porque é muito frequente, no país, a violação das normas de proteção da saúde com a colocação de produtos no mercado de consumo sem atenção aos requisitos. Em 2001 e 2002, a ANVISA dispôs em regulamentos, por meio de resoluções, sobre as regras relativas aos diversos produtos enquadrados na legislação como correlatos, atuais produtos para saúde, segundo a nova nomenclatura. Aparelhos tais como bicicletas ergométricas, esteiras ergométricas, elípticas e demais equipamentos para práticas desportivas em ambientes domiciliares ou em academias de ginástica não são considerados produtos para saúde; assim, não estão sujeitos a registro ou cadastramento na ANVISA, segundo a RDC 260, de 23 de setembro de 2002. Contudo, produtos que têm interação com seres humanos, os eletroestimuladores musculares, aparelhos indicados para fisioterapia ou para diagnóstico médico (avaliação clínica), aparelhos enquadrados em qualquer grau de risco, são considerados produtos para saúde e, portanto, devem ser registrados, conforme estabelece a RDC 185, de 22 de outubro de 2001, exatamente porque oferecem riscos à saúde.

Atualmente, têm sido colocados no mercado de consumo diversos produtos para atividade física, embelezamento ou estética. Os padrões de beleza física propagados nos meios de comunicação de massa e a busca

(4) Art. 36. O registro dos aparelhos, instrumentos e acessórios de que trata o artigo anterior será obrigatório quando a sua utilização dependa de prescrição médica, de cuidados especiais de aplicação ou da observação de precauções, sem as quais possam produzir danos à saúde. 
por saúde constituem estímulos para as empresas que procuram promover inovações e ofertá-las ao consumo, provocando a necessidade de atualização das normativas, mas também de atuação dialógica da vigilância sanitária, visando à comunicação de riscos ${ }^{(5)}$ envolvidos nos objetos de consumo, para ser efetiva na proteção da saúde individual e coletiva.

\section{REFERÊNCIAS BIBLIOGRÁFICAS}

COSTA, E. A. Vigilância sanitária: proteção e defesa da saúde. São Paulo: Sobravime, 2004.

LEFÈVRE, F. Mitologia sanitária. São Paulo: Edusp, 1999.

RANGEL-S, M. L.; MARQUES, T.; COSTA E. A. Risco, vigilância sanitária e comunicação: subsídios para uma política de proteção e promoção da saúde. In: COSTA E. A.; RANGEL-S, M. L. (Orgs.) Comunicação em vigilância sanitária: princípios e diretrizes para uma política. Salvador: Edufba, 2007. p.13-39.

(5) RANGEL-S, M. L.; MARQUES, T.; COSTA E. A. Risco, vigilância sanitária e comunicação: subsídios para uma política de proteção e promoção da saúde. In: COSTA E. A.; RANGEL-S, M. L. (Orgs.) Comunicação em vigilância sanitária: princípios e diretrizes para uma política. Salvador: Edufba, 2007. p.13-39. 